\title{
S Wave Abnormality by ECG Finding
}

National Cancer Institute

\section{Source}

National Cancer Institute. S Wave Abnormality by ECG Finding. NCI Thesaurus. Code C90451.

An electrocardiographic finding of an atypical S wave within the QRS complex; it is due to a disturbance in the depolarization of the ventricular myocardium. 